\title{
Aceleradores e detectores de partículas no ensino médio: uma sequência de ensino-aprendizagem ${ }^{+*}$
}

\author{
Yasmin Alves dos Reis Silva ${ }^{1}$ \\ Larruana Montanha ${ }^{1}$ \\ Maxwell Roger da Purificação Siqueira ${ }^{1}$ \\ Universidade Estadual de Santa Cruz \\ Ilhéus - BA
}

\section{Resumo}

O presente artigo apresenta uma proposta de sequência de ensino e aprendizagem sobre Aceleradores e Detectores de Partículas (ADP), pautado na discussão sobre a inserção de tópicos de Física Moderna e Contemporânea (FMC) na educação básica. A proposta utilizou o referencial teórico-metodológico da Teaching Learning Sequences (TLS) fundamentada na Design Based Research (DBR), que visa a construção da sequência a partir de um processo cíclico que desenvolve, aplica e reconstrói sequências baseadas em tópicos específicos. Após construção, a sequência foi implementada em uma escola pública federal, em turmas da 3 a série do Ensino Médio. As informações coletadas foram analisadas tendo em vista as fases da estrutura didática (protoprincípio de design) propostas no referencial de construção desse tipo de sequência, permitindo avaliá-la e redesenhá-la para uma nova implementação. Nesta análise foi possível encontrar lacunas de aprendizagem e a necessidade de sistematização do conhecimento, porém permitiu encontrar indicios de apropriação de conhecimentos científicos pelos estudantes, que é um indicativo de potencialidade da sequência.

Palavras-chave: Física Moderna e Contemporânea; Teaching Learning Sequences; Transposição Didática; Aceleradores e Detectores de partículas.

\footnotetext{
${ }^{+}$Accelerators and particle detectors in high school: a sequence of teaching-learning

* Recebido: julho de 2019. Aceito: maio de 2020.

${ }^{1}$ E-mails: yasmin.fisica@gmail.com; lahuanamontanha@gmail.com; maxwell_siqueira@hotmail.com
} 


\begin{abstract}
This article presents a proposal for a teaching and learning sequence on Accelerators and Particle Detectors (ADP), based on the discussion on the insertion of Modern and Contemporary Physics (MCP) topics in basic education. The proposal used the theoretical-methodological reference of Teaching Learning Sequences (TLS) supported by Design Based Research (DBR), which aims to build the sequence from a cyclic process that develops, applies and reconstructs sequences based on specific topics. After construction, the sequence was implemented in a federal public High School, in grade 12 classes. The information collected was analyzed considering the phases of the didactic structure (design protoprinciple) proposed in the referential of construction of this type of sequence, allowing it to be evaluated and redesigned it for a new implementation. In this analysis it was possible to find learning gaps and the need for systematization of knowledge, on the other hand appropriation of scientific knowledge by students, which is an indicator of the potentiality of the sequence.
\end{abstract}

Keywords: Modern and Contemporary Physics; Teaching-Learning Sequence; Didactic Transposition; Accelerators and Particle Detectors.

\title{
I. Introdução
}

Nos últimos anos, a discussão sobre a melhoria do ensino de Ciências tem se intensificado devido ao baixo desempenho dos estudantes brasileiros relacionado ao conhecimento científico, o que tem gerado constantes questionamentos sobre a falta de eficiência inerente ao processo de ensino e aprendizagem. De um lado, percebe-se que há uma demanda social, que exige uma melhoria na qualidade do ensino. Por outro, uma demanda científica, devido ao desenvolvimento científico que, em sua maioria não está presente na sala de aula (SIQUEIRA, 2012).

Especificamente com a Física, nota-se que há uma necessidade de atualização dos conteúdos a serem ensinados, porque os conceitos de física presentes em sala de aula não ultrapassam o século XIX, levando a uma grande desarticulação entre o que a Ciência produz de conhecimento e aquele que é ensinado na escola. Nesse sentido, Terrazzan (1992) já destacava que a grande maioria dos tópicos de física na educação básica está compreendida entre anos de 1600 e 1850, que estão relacionados com a Física Clássica. Vivemos no século XIX mas a física escolar não passa do século XIX. Ondas gravitacionais, buracos negros, radiação cósmica, energia nuclear, LHC são exemplos de termos relacionados a física que permeiam os noticiários, porém não estão presentes na sala de aula. 
Nesse sentido os conhecimentos científicos, especialmente aqueles relacionados à Física Moderna e Contemporânea (FMC), foram e são relevantes para se alcançar o atual nível tecnológico em que o mundo se encontra, que revolucionaram a forma de pensar a construção do conhecimento científico dificilmente têm espaço para serem discutidas em sala de aula (SIQUEIRA; PIETROCOLA, 2006).

Entretanto, embora os estudos sobre a inserção da FMC tiveram um aumento gradativo na última década (PIETROCOLA, 2010; MONTEIRO, NARDI, BASTOS FILHO, 2012), a literatura aponta a necessidade da produção de materiais que deem suporte aos professores para o ensino da temática, ou seja, materiais didáticos que tenham respaldo para a sua implementação na sala de aula (PEREIRA; OSTERMANN, 2009; PIETROCOLA, 2010; LOCH; GARCIA, 2009; ARAÚJO; HOSOUME, 2013; KNEUBIL, 2014; BATISTA; SIQUEIRA, 2017). Ademais, é preciso investir no processo de elaboração e validação de materiais didáticos sobre tópicos de FMC fundamentados em referenciais que visem à aprendizagem (PEREIRA; OSTERMANN, 2009).

Alinhado a essa discussão, e a partir das considerações mencionadas anteriormente, propõe-se como objetivo geral da presente artigo investigar a potencialidade de uma Sequência de ensino-aprendizagem em torno do tema Aceleradores e Detectores de Partículas (ADP), visando auxiliar o processo de atualização do currículo, no contexto escolar. O que nos guia a refletir em torno do seguinte questionamento: Como abordar os Aceleradores $e$ Detectores de Partículas, de maneira a levar esse conhecimento para a sala de aula, fundamentados em referenciais que favoreçam o processo de ensino-aprendizagem?

Nesse contexto, apresentamos uma Sequência de Ensino-Aprendizagem (SEA) sobre Aceleradores e Detectores de Partículas que foi implementada em sala de aula. Tal Sequência está fundamentada nos pressupostos teórico-metodológicos da Teaching-Learning Sequence (TLS) e na teoria da Transposição Didática (TD), auxiliando-nos nas escolhas de como organizaríamos o conteúdo da Sequência com o intuito de completar o processo que envolve as três vertentes TD, TLS e Design-Based Research (DBR) - Pesquisa Baseada em Design (COLLECTIVE, 2003), de onde descendem as pesquisas do tipo TLS.

No que se refere a escolha dos ADP como tema, temos alguns fatores a serem destacados. O primeiro está relacionado ao quantitativo de pesquisas que abordam esse assunto, que ainda são discretas. É possível observar no trabalho de Pereira e Ostermann (2009) que em 102 artigos analisados na área de ensino nenhum deles envolvia os ADP como tema principal.

Em análise sobre os tópicos de FMC que seriam pertinentes para serem trabalhados no ensino médio, Pietrocola (2010) destaca três a serem privilegiados: a interação matériaradiação, as Partículas Elementares e a Teoria da Relatividade. Nesse sentido, entendemos que a escolha dos ADP como tema principal da sequência, sendo possível o enfoque desde as micropartículas investigadas pelos ADP, até as diversas implicações tecnológicas que os 
mesmos possibilitam, como o avanço nos exames diagnósticos para a medicina, contemplando, tanto as partículas elementares, como a interação entre a matéria e a radiação.

Em uma outra perspectiva, pensando nas relações entre a ciência, a tecnologia e a sociedade, os aceleradores de partículas são um dos mais grandiosos instrumentos já construídos pelo ser humano, em que estão envolvidas as principais pesquisas científicas de fronteira. Nessa direção Ostermann e Moreira (2001) ressaltam a pertinência de se tratar o tópico na formação científica do cidadão.

Cabe ainda destacar ainda que ao falar dos ADP estamos tratando de um objeto de investigação pertencente a uma ciência atual e vigente, que abarca os conhecimentos desenvolvidos no CERN (Centro Europeu de Pesquisas Nucleares), onde se encontra um dos principais aceleradores de partículas e mais divulgados pela mídia, o Grande Colisor de Hádrons (em inglês: Large Hadron Collider) - LHC, que é um dos maiores e mais custosos empreendimentos no âmbito científico, que tem possibilitado a investigação dos pilares dos constituintes da matéria.

Assim, ao abordar a Física presente no CERN pode permitir a mudança de visão rígida da ciência, construída de maneira linear e hierárquica tratando de conteúdos e conceitos tanto referentes a física moderna (descoberta, colisão e detecção das partículas, compreensão sobre a constituição da matéria, e outros) como a física clássica (diferença de potencial, campo elétrico, campo magnético, conservação de energia, e outros) ressaltando não ser necessário abandonar o conhecimento clássico em detrimento do moderno, uma vez que ambos continuam válidos para a compreensão de alguns fenômenos como o próprio funcionamento dos ADP.

\section{A Pesquisa baseada em Design (DBR) e a Sequência de Ensino-Aprendizagem}

Da necessidade de elaboração de materiais fundamentados em referenciais que visem a aprendizagem, a sequência construída, implementada, analisada e reestruturada nesta pesquisa, é baseada na abordagem metodológica da Teaching Learning Sequences (TLS), enunciada pela primeira vez nos estudos de Lijnse (1994).

Dentre as características que compõem esse tipo de sequência, destaca-se que as sequências baseadas na $T L S$ são passíveis de mudanças, uma vez que há a necessidade de reaplicá-las e avaliá-las em diferentes contextos (LIJNSE; KLAASSEN, 2004). As modificações ocorridas nessas $T L S$ encontram alicerce na abordagem metodológica conhecida como Pesquisa Baseada em Design - do inglês Design-Based Research (DBR), que se definem como uma metodologia de pesquisa capaz de associar perspectiva teórica com aplicações educacionais práticas, como afirmam os autores

Métodos da Design-Based Research podem compor uma metodologia coerente que liga pesquisas teóricas à prática educacional. Vislumbrando ao mesmo tempo o design de uma intervenção e suas especificações como objetos de pesquisa, pode pro- 
duzir explicações robustas sobre práticas inovadoras e fornecer princípios que podem ser usados por outros, para serem aplicados em novas configurações. DesignBased Research, fundamentando-se em suas próprias necessidades, restrições e interações de práticas locais, podendo prover uma lente para a compreensão de como demandas teóricas sobre o ensino e a aprendizagem pode ser transformadas em aprendizagem eficaz em ambientes educacionais (DBR-COLLECTIVE, 2003, p. 8, tradução nossa).

Essa abordagem metodológica surge na década de 90, unindo aspectos teóricos de pesquisas com aplicações na prática em sala de aula, sendo introduzida no âmbito da educação por Brown e Collins, em 1992, quando simultaneamente outros autores passaram a usar termos parecidos se referindo a um desenvolvimento didático (KNEUBIL, 2014). Nesse contexto, surgem diversos artigos tratando das inovações de conteúdos curriculares particularmente nos currículos de ciências, com 32 Sequências de Ensino-Aprendizagem (SEA) com tópicos do ensino de ciências, em áreas como a óptica, calor, eletricidade, estrutura da matéria e outras (KATTMANN et al., 1995; LEACH; SCOTT, 2002; COLLECTIVE, 2003; LIJSEN; KLAASSEN, 2004; MÈHEUT; PSILLOS, 2004; TIBERGHIEN, 2009).

As sequências estão inseridas em uma nova perspectiva de pesquisas de educação científica pela qual o ensino e a aprendizagem são investigados em um nível micro, ou seja, Sequências curtas sobre tópicos específicos, denominadas de Teaching Learning Sequences (TLS). Uma característica relevante dessas sequências é que o próprio processo de construção das mesmas é, em si, um objeto de investigação permitindo analisar o processo de EnsinoAprendizagem de um tópico particular (MÈHEUT; PSILLOS, 2004).

Destaca-se que a relação entre as pesquisas teóricas com a prática educacional da DBR e TLS é mencionada, por diversos autores, como relevante por auxiliar na compreensão e promoção de ações que favoreçam o processo de ensino-aprendizagem (COLLECTIVE, 2003; PIETROCOLA, 2010; NICOLAU; GURGEL, 2013; KNEUBIL, 2014; BATISTA, 2015). De acordo com Pessanha e Pietrocola (2016), a DBR tem a perspectiva de analisar os resultados de uma intervenção planejada e inovadora, propondo-se ir além quanto à intenção de investigar a natureza da aprendizagem. Em um sentido amplo, a ideia da DBR e $T L S$ leva em consideração a construção, implementação, avaliação e reestruturação de sequências. Nesse sentido, Collective (2003) destaca que as pesquisas baseadas em $D B R$, planejadas a partir da $T L S$, possuem cinco características importantes que orientam o seu desenvolvimento da mesma.

A primeira é sobre a necessidade dos princípios fundamentais - denominados como protoprincípios de Design - que orientam o desenho da Sequência e a importância de essa está associada aos seus objetivos centrais, representando a necessidade de controle nos parâmetros por parte do pesquisador e favorecendo o alcance dos objetivos.

A segunda diz respeito à "validação" da Sequência enquanto $T L S$, que só acontecerá se passar pelos processos cíclicos de desenho, implementação, análise e redesenho, analisando as modificações necessárias e implementando-a em um contexto diferente. Esse processo po- 
de ser realizado de duas formas, uma é por meio dos procedimentos de pré-teste e pós- teste, quando a metodologia adotada visa provar a eficácia de um ensino em comparação a outros, sendo chamada de avaliação "externa". A outra, avaliação interna, tem por objetivo testar a eficácia da sequência em relação aos objetivos iniciais.

No caso do artigo a validação é interna, pois o interesse não houve interesse em comparar grupos, mas sim em avaliar e melhorar o processo que envolve a sequência de ensino-aprendizagem, ou seja, utilizou-se de atividades processuais visando investigar como a sequência se apresentou para os alunos, verificando por meio das atividades o conhecimento que possuíam e passaram a ter após a implementação da mesma.

A terceira se refere à qualidade dos resultados, orientando que eles sejam compartilháveis e relevantes a professores e demais pesquisadores.

A quarta característica refere-se ao contexto de aplicação das Sequências, orientando que estas sejam compatíveis com a realidade do ensino que se deseja prover, ou seja, adequadas ao contexto, bem como que os seus resultados incluam seu processo interativo entre professor e pesquisador na produção e implementação da mesma.

Por fim, a quinta indica a importância de registrar e assegurar a conexão entre os resultados e as implementações das Sequências de Ensino-Aprendizagem, remetendo, mais uma vez, aos objetivos pretendidos bem como à divulgação dessas Sequências como efeito de registro.

Dentre os principais aspectos da $T L S$, destaca-se o fato da mesma possuir um tema específico e não representar um currículo estendido, já que a TLS propõe uma sequência com duração de poucas semanas (MÉHEUT; PSILLOS, 2004). Para projetar a TLS, além de esta ser desenvolvida a partir de tópicos específicos, curtos, com no máximo doze aulas e passível de ser implementada em diferentes contextos, o que implica diretamente em sua 'qualidade', é necessário, também, que esteja associada a seis fases que orientam o processo de sua construção.

Nesse sentido, Lijnse e Klaassen (2004) postulam seis fases para estruturar o desenho ou desenvolvimento da TLS, tendo como protoprincípio de design o modelo da "estrutura didática" (LIJNSE; KLAASSEN, 2004, p. 543-544).

Fase 1 - Traz a necessidade de orientar e mencionar o interesse global, ou seja, o motivo do estudo do tema em apreço, e como ele se apresenta em relação à vida dos estudantes, ou seja, quais as concepções prévias que os alunos têm sobre este. Tais motivos são vistos como relevantes para o delineamento das próximas fases. Nesse sentido, parte-se da ideia que a construção de novos conhecimentos se pauta no conhecimento já existente, isso implica que, se devidamente interpretada, sempre podemos encontrar um começo para o processo de ensino (LIJNSE; KLAASSEN, 2004).

Fase 2 - Leva em consideração a Fase 1, estreitando o motivo global de maneira a despertar o interesse dos estudantes em direção ao conhecimento. Sobre essa fase, é possível acrescentar que é importante enxergar a Ciência como uma construção humana, e, consequen- 
temente, este ensino deve orientar o aluno a entender as atividades científicas em seu modo, ao invés de transferir esses conhecimentos como um produto pronto e acabado, representando uma abordagem de Ensino-Aprendizagem problematizadora (LIJNSE; KLAASSEN, 2004).

Fase 3 - Visa o processo de evolução dos conhecimentos prévios dos estudantes para conhecimentos mais elaborados, no que se refere ao caráter científico do conhecimento, levando em conta o caráter problematizador.

Fase 4 - constitui a aplicação do conhecimento em situações distintas, visando à resolução de problemas, seja na vida ou em sala de aula, sobre o tópico em questão. É nessa fase que os estudantes, já de posse de alguns conhecimentos, posicionar-se-ão sobre as implicações cotidianas relacionadas ao tema (LIJNSE; KLAASSEN, 2004).

Fase 5 - é um momento que o professor deve auxiliar os estudantes na reflexão sobre os conhecimentos científicos estudados, gerando a necessidade de uma orientação teórica para a busca de conhecimentos (LIJNSE; KLAASSEN, 2004).

Fase 6 - estabelece que o professor e os estudantes devem aprofundar-se no processo de construção dos conhecimentos objetivados, fazendo uso dos conceitos e termos científicos para a compreensão do tema. (LIJNSE; KLAASSEN, 2004).

A importância do conhecimento científico a ser apresentado no desenho da TLS, conforme Lijnse e Klaassen (2004), envolve justificativas teóricas que se referem ao apontamento de pesquisas sobre a necessidade de o conhecimento ser tratado em uma perspectiva problematizadora (hipótese de design), relacionado com o contexto em que professores e alunos estão inseridos. Dessa forma, não há como não pensar nessa perspectiva sem se referir à importância de problematizar o conhecimento, levando em consideração os conhecimentos prévios e a realidade dos estudantes. Nessa direção, Batista e Siqueira (2017, p. 885) destacam que

a hipótese de design não só expressa a intima relação entre os objetivos centrais da TLS com as teorias educacionais, como também evidencia que, ao longo das fases, o objetivo central é o estreitamento entre os conhecimentos prévios dos estudantes e o conceito científico que se deseja ensinar.

Essa perspectiva problematizadora pode ser encontra nos três momentos pedagógicos (3MP), proposto por Delizoicov, Angotti e Pernambuco (2011). Esses três momentos podem auxiliar, de maneira significativa, na construção da $T L S$, uma vez que este referencial não determina, de forma específica, sobre como desenvolver as atividades e, ao mesmo tempo, traz afinidade com relação à necessidade de problematização. Os pesquisadores Delizoicov, Angotti e Pernambuco (2011) estruturam os 3MP com relação ao desenvolvimento das atividades em sala de aula, denominando-os como: Problematização Inicial, Organização do Conhecimento e Aplicação do Conhecimento. Segundo Delizoicov, Angotti e Pernambuco (2011), na Problematização Inicial, devem ser apresentadas aos alunos situações reais que sejam de seu conhecimento e que estejam envolvidas nos temas, de modo que esse momento 
seja organizado para que os alunos sejam desafiados a fazer uma exposição do que estão pensando sobre as situações apresentadas.

Já a Organização do Conhecimento é o momento para que os conhecimentos, que são necessários à compreensão dos temas bem como da problematização inicial, possam ser sistematicamente estudados, sob a orientação do professor. Assim, "as mais variadas atividades são então empregadas, de modo que o professor possa desenvolver a conceituação identificada como fundamental para uma compreensão crítica das situações problematizadas" (DELIZOICOV; ANGOTTI; PERNAMBUCO, 2011, p.201).

Por fim, na Aplicação do Conhecimento, deve-se fazer uma abordagem sistemática do conhecimento que está sendo incorporado pelos alunos, buscando-se analisar as situações iniciais que determinaram seu estudo, além de outras circunstâncias que também podem ser compreendidas, lançando mão do mesmo conhecimento, ou seja, chama-se atenção para a capacidade do aluno em mobilizar os conhecimentos produzidos na resolução do problema inicial.

De acordo com Muenchen e Delizoicov (2014), ao longo dos anos, os 3MP foram revistos e extrapolaram sua utilização inicial apenas para o desenvolvimento de atividades em sala de aula, sendo utilizados de maneiras diferentes, como na elaboração de material didático para cursos de graduação, estruturadores/organizadores de discussões em eventos e como metodologia do ensino de ciências, proporcionando à educação científica um avanço no que se refere ao ensino tradicional, devido à motivação da participação das pessoas, por conta do caráter problematizador. Dessa forma, utilizamos os 3MP como metodologia para a construção dos momentos de aula da Sequência uma vez que a TLS visa trazer conteúdos inovadores do ensino de Ciências, conteúdos estes que ainda se fazem, por muitas vezes, distantes da realidade escolar, como os conteúdos da FMC (COLLECTIVE, 2003; PIETROCOLA, 2010; NICOLAU; GURGEL, 2013; KNEUBIL, 2014; BATISTA; SIQUEIRA, 2017).

Percebe-se que os 3 MP têm uma relação com as fases da estrutura didática, que é o protoprincípio de design da sequência sobre ADP aqui proposta, uma vez que ambas visam a evolução do conhecimento científico pelo estudante, a partir de problemas próximos de seu cotidiano, sendo possível aplicá-lo a novos contextos. Além disso, consideram suas concepções prévias como ponto de partida para a discussão dos conceitos científicos.

Nesse sentido, Méheut e Psillos (2004) destacam critérios importantes para o desenvolvimento da sequência a serem levados em consideração, incluindo duas dimensões, uma epistemológica (eixo vertical), que representa o conhecimento científico a ser avaliado com relação ao mundo material e, uma dimensão pedagógica (eixo horizontal) que envolve os interesses e papel entre aluno e professor, conforme representado na Fig. 1 a seguir. 


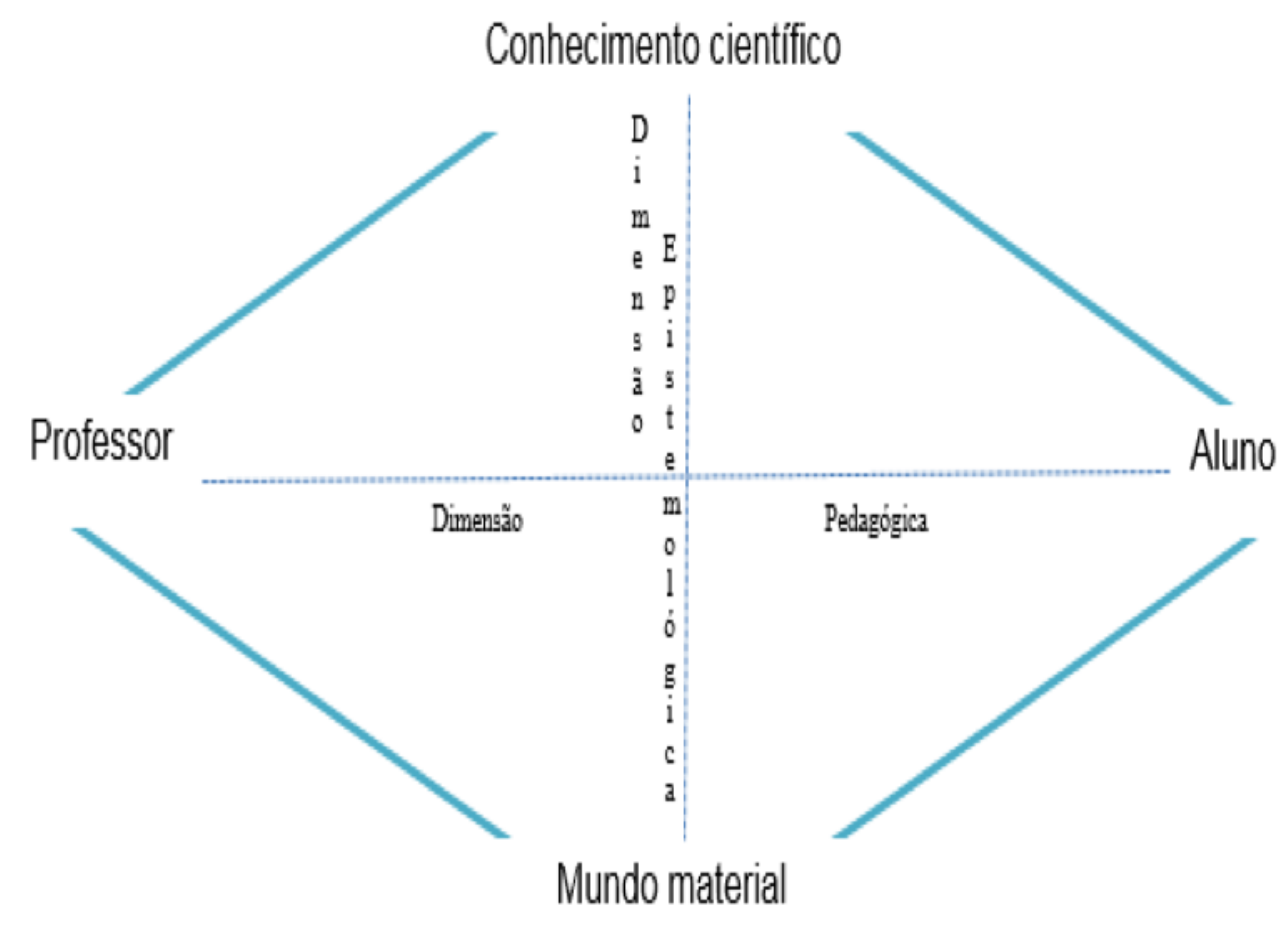

Fig. 1 - Dimensões para o desenvolvimento da sequência- (MÉHEUT; PSILLOS, 2004, p. 517, tradução própria).

Os autores complementam ainda que entre os vértices acontecem outras interações, como a relação do aluno com o conhecimento, do aluno com o mundo material, do aluno com o professor. Logo, essa representação possibilita a organização de várias considerações tanto combinando as duas dimensões como entrelaçando-as.

\section{Algumas relações entre a Transposição Didática e a Teaching Learning Sequences}

É possível estabelecer algumas relações entre a teoria da Transposição Didática (TD) e a $T L S$, dentre estas, é possível primeiro refletir sobre o ensino do tópico Aceleradores e Detectores de Partículas (ADP) a partir da teoria da Transposição Didática, em busca das melhores escolhas para transformar esse conhecimento para o contexto escolar. Para tanto, levam-se em conta as características e regras estabelecidas pela TD, relacionadas com a sobrevivência do saber, bem como a necessidade de ter em vista os contextos e considerações importantes para compreender os ADP, conhecimento científico fruto de esfera denominada "Saber Sábio", que se constituíra como conhecimento na esfera do "Saber a Ensinar" quando a SEA estiver desenvolvida, sendo apresentado futuramente na esfera do "Saber Ensinado", após implementação na sala de aula. A Fig. 2, a seguir, representa essas esferas do saber na TD, segundo Chevallard (1991). 


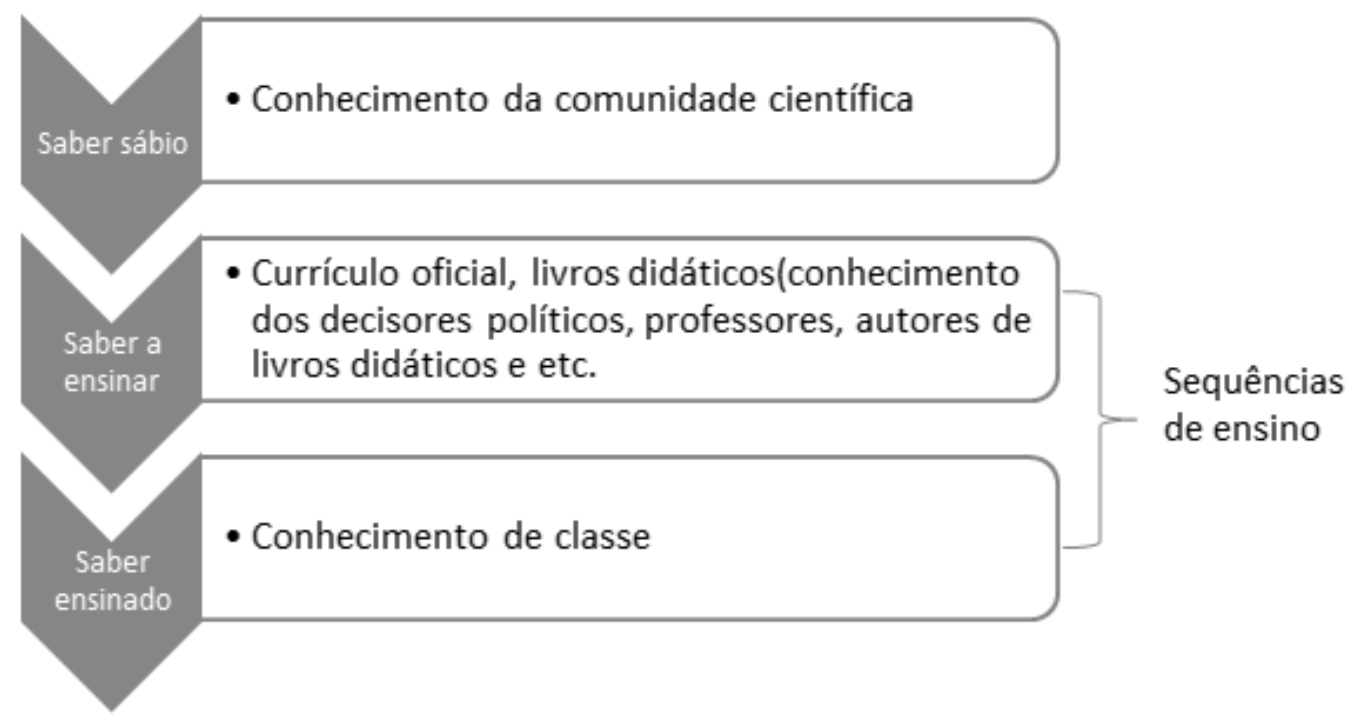

Fig. 2 - Esferas do saber.

Um aspecto importante no nível do "Saber a Ensinar", que compreende a sequência, é que esse material, diferentemente da tradição linear e hierárquica dos livros didáticos mencionada, é flexível e passa por constantes e cíclicos processos de modificações em busca de apresentar-se cada vez mais adequado às necessidades do processo de Ensino-Aprendizagem (PIETROCOLA, 2010). Consideramos, então, alguns livros, textos e materiais acadêmicos (artigos, dissertações e teses) como material de referência para a construção da SEA.

Entendemos, a partir das inferências mencionadas, que a $T L S$ e a TD se complementam, reduzindo algumas lacunas existentes no processo de ensino-aprendizagem, uma vez que a $T L S$ se caracteriza como fruto de uma Pesquisa Baseada em Design, que orienta o processo que envolve o desenho de sequências com as práticas da educação. Dessa forma, torna-se um elo entre as duas últimas esferas do saber da TD, permitindo olhar a esfera do "Saber Ensinado" em uma perspectiva mais profunda, ao mesmo tempo em que a TD fornece os cuidados e atenção necessária para o Design da TLS. Assim sendo, pode-se perceber que a TD se constitui como uma grande teoria que contribui com a Pesquisa Baseada em Design (DBR), que envolve propostas como a TLS (TIBERGHIEN et al., 2009).

Nesse sentido, é possível enxergar na TD as condições sociais da existência do conhecimento (TIBERGHIEN et al., 2009). Contudo, caso queira avaliar a aprendizagem, faz-se interessante utilizar uma teoria específica, como o sócio interacionismo de Vygotsky, levando em consideração que a sala de aula permitirá que os alunos construam significados em um plano social em que o desenvolvimento cultural (ciência) poderá ter lugar e será favorecido pela mediação da linguagem e de outras pessoas, como o professor e demais estudantes.

Nessa direção, mais relevante do que o conhecimento em si são as relações com que os mesmos são construídos. A partir de suas análises, Tiberghien et al. (2009) inferem que, na maior parte do tempo, os alunos, no final da $T L S$, constroem um conhecimento intermediário 
entre o conhecimento inicial e o objetivado. Esse processo de construção do conhecimento durante uma sequência pode ser bem interpretado se a análise da sala de aula e do discurso dos estudantes foi realizada detalhadamente. Dessa forma, a função da TLS é fornecer aos alunos a oportunidade de entender sobre um novo elemento do conhecimento progressivamente.

\section{Contexto da implementação}

O design da sequência aconteceu de forma colaborativa, por meio de conversas com alguns dos membros do grupo de pesquisa (professor formador, professor da escola e outros pós-graduandos), visando as melhores escolhas para o delineamento dela, e entendendo que esse caminho favorece o processo de sua construção e implementação. A Sequência foi implementada junto à escola pública federal e parceira de projetos de pesquisa, com a colaboração do professor de Física da escola que, como integrante do grupo de pesquisa, auxiliou na pesquisa com ideias durante o design da sequência, contribuindo inclusive na construção de uma das atividades principais (câmara de nuvens), pois o mesmo já havia visto o experimento em funcionamento durante a participação da escola de Física do CERN, no ano de 2014, promovida pela Sociedade Brasileira de Física (SBF).

As turmas que participaram do processo inicial da pesquisa foram duas do terceiro ano do Ensino Médio, com faixa etária entre 16 e 18 anos. A escolha do nível escolar aconteceu no processo inicial da pesquisa, pois tanto pesquisadora como membros do grupo de pesquisa entenderam que esse nível teria alguns pré-requisitos necessários para a abordagem, já tendo visto conteúdos sobre energia e constituição da matéria. A implementação ocorreu com duas turmas, uma do curso técnico em guia de turismo com 15 alunos matriculados e outra de informática com 22 alunos, no ano letivo de 2016.

Como instrumentos de obtenção de informações, fizemos uso das atividades processuais desenvolvidas em sala de aula com os alunos, e das gravações em vídeo das aulas que foram transcritas. Destacamos que as filmagens da sequência se iniciavam assim que os alunos entravam na sala e só terminavam após o último aluno sair, exceto na visita técnica a um laboratório de pesquisa em radiação, em uma Instituição de Ensino Superior próxima à escola, pois não tivemos como fazer uso da gravação, sendo registrado por meio do diário - anotações do pesquisador - e fotos.

Para manter a identidade preservada dos alunos, utilizamos códigos para as atividades processuais e transcrições: a letra "A" acompanhada com os números que indicam cada aluno; a palavra "vários", quando os alunos respondem ao professor juntos; e quando o professor fala está representado pela letra "P". É importante salientar que o pesquisador fez o mínimo de inferência possível durante os encontros. 


\section{Os caminhos e análises da sequência de Ensino-Aprendizagem}

A partir dos pressupostos da $T L S$, o tema específico foi selecionado: Aceleradores e Detectores de Partículas (ADP). De acordo com as características importantes para a orientação do desenvolvimento da SEA, baseado em Collective (2003), foi realizado o Design de um piloto da SEA, a qual está fundamentada nos 3MP e no modelo de estrutura didática, e dividida em 4 momentos e com 12 aulas (quadro 1).

Quadro 1 - Resumo do primeiro desenho da Sequência de Ensino-Aprendizagem sobre aceleradores e detectores de partículas.

\begin{tabular}{|c|c|c|c|}
\hline Momentos & Objetivos & Conceitos envolvidos & Estratégias de ensino \\
\hline $\begin{array}{l}\text { Momento A } \\
\text { ( } \text { aulas) }\end{array}$ & $\begin{array}{l}\text { - Entender a relação existente } \\
\text { entre o experimento câmara } \\
\text { de nuvens com os acelera- } \\
\text { dores e Detectores de Partí- } \\
\text { culas (ADP); } \\
\text { - Desmistificar os raios cós- } \\
\text { micos; } \\
\text { - Compreender o que são os } \\
\text { raios cósmicos e relacioná- } \\
\text { los com os Aceleradores e } \\
\text { Detectores de Partículas. }\end{array}$ & $\begin{array}{l}\text { Partículas subatômicas, } \\
\text { raios cósmicos e radiação } \\
\text { ionizante. }\end{array}$ & $\begin{array}{l}\text { - Apresentação de trechos } \\
\text { de mensagens da internet, } \\
\text { destacando o "perigo" } \\
\text { dos raios cósmicos; } \\
\text { - Apresentação e discussão } \\
\text { de fenômenos e aspectos } \\
\text { envolvidos na construção } \\
\text { e funcionamento do expe- } \\
\text { rimento câmara de nu- } \\
\text { vens, bem como as rela- } \\
\text { ções existentes entre a } \\
\text { mesma com os ADP. }\end{array}$ \\
\hline $\begin{array}{l}\text { Momentos B } \\
\text { ( } 4 \text { aulas) }\end{array}$ & $\begin{array}{l}\text { - Perceber a importância dos } \\
\text { experimentos controlados } \\
\text { para a Ciência; } \\
\text { - Compreender as principais } \\
\text { características dos ADP; } \\
\text { - Compreender o funciona- } \\
\text { mento de alguns dos princi- } \\
\text { pais ADP. }\end{array}$ & $\begin{array}{l}\text { Tipos de Aceleradores e } \\
\text { Detectores de Partículas, } \\
\text { bem como os conceitos } \\
\text { físicos que envolvem o seu } \\
\text { funcionamento, tais como: } \\
\text { - Diferença de potencial; } \\
\text {-Campo elétrico; } \\
\text {-Campo magnético; } \\
\text {-Conservação de energia }\end{array}$ & $\begin{array}{l}\text { - Leitura, análise e discus- } \\
\text { são a partir de um texto } \\
\text { sobre raios cósmicos e os } \\
\text { ADP; } \\
\text { - Fornecimento de materi- } \\
\text { ais para que os alunos } \\
\text { tentem modelizar os tipos } \\
\text { de ADP; } \\
\text { - Discussão a partir de um } \\
\text { texto sobre as implica- } \\
\text { ções tecnológicas a partir } \\
\text { dos estudos desenvolvi- } \\
\text { dos nos ADP. }\end{array}$ \\
\hline
\end{tabular}




\begin{tabular}{|c|c|c|c|}
\hline $\begin{array}{l}\text { Momento C } \\
\text { ( } 4 \text { aulas) }\end{array}$ & $\begin{array}{l}\text { - Entender as consequências } \\
\text { de um investimento tão alto } \\
\text { como o LHC para a socie- } \\
\text { dade moderna; } \\
\text { - Visitar um centro de pes- } \\
\text { quisa que envolve os estu- } \\
\text { dos de física das radiações } \\
\text { e/ou física médica; } \\
\text { - Compreender as relações } \\
\text { que existem entre os ADP e } \\
\text { a sociedade; } \\
\text { - Entender os motivos para } \\
\text { realização de investimentos } \\
\text { tão elevados em pesquisas } \\
\text { científicas; } \\
\text { - Conhecer o centro de pes- } \\
\text { quisas em ciências e tecno- } \\
\text { logias das radiações. }\end{array}$ & $\begin{array}{l}\text { - Física das radiações } \\
\text { e/ou física médica; } \\
\text { - Tecnologias dos acele- } \\
\text { radores e detectores de } \\
\text { partículas; } \\
\text {-Equipamentos radiodi- } \\
\text { agnósticos. }\end{array}$ & $\begin{array}{l}\text { - Apresentação de textos e } \\
\text { vídeos que envolvem os } \\
\text { aspectos tecnológicos da } \\
\text { sociedade moderna que } \\
\text { foram influenciados ou } \\
\text { ocasionados a partir dos } \\
\text { estudos nos ADP; } \\
\text { - Os alunos conhecerão um } \\
\text { centro de pesquisa em ci- } \\
\text { ências e tecnologias da } \\
\text { radiação, próximo às suas } \\
\text { escolas, bem como os ex- } \\
\text { perimentos desenvolvidos } \\
\text { neste centro. }\end{array}$ \\
\hline $\begin{array}{l}\text { Momento D } \\
\text { ( } 2 \text { aulas) }\end{array}$ & $\begin{array}{l}\text { - Relacionar os conhecimen- } \\
\text { tos físicos com outras áreas } \\
\text { do conhecimento; } \\
\text { - Associar conhecimentos } \\
\text { físicos com situações do co- } \\
\text { tidiano. }\end{array}$ & $\begin{array}{l}\text { Não há um conteúdo especí- } \\
\text { fico, uma vez que esta aula } \\
\text { trata da culminância do } \\
\text { curso, em que os alunos irão } \\
\text { apresentar os trabalhos por } \\
\text { eles produzidos a partir de } \\
\text { tudo que foi tratado durante } \\
\text { a SEA, contemplando os } \\
\text { conteúdos mencionados nas } \\
\text { demais aulas. }\end{array}$ & $\begin{array}{l}\text { Este encontro trata da cul- } \\
\text { minância do curso. Nesta } \\
\text { ocasião, serão apresentados } \\
\text { os trabalhos desenvolvidos } \\
\text { pelos alunos. }\end{array}$ \\
\hline
\end{tabular}

Inicialmente, implementamos uma atividade diagnóstica ${ }^{2}$ para sondar o que os alunos conheciam dos ADP, pois descobrimos que estes já haviam ouvido falar dos ADP na aula com o professor, o qual visitou o Centro Europeu de Pesquisas Nucleares (CERN), onde se encontram os principais ADP do mundo, a exemplo do Grande Colisor de prótons, conhecido como LHC, e seus detectores, como o ALICE e o LHCb.

Essa etapa foi desenvolvida a partir da primeira fase destacada no modelo de pesquisa e desenvolvimento. Em relação à estrutura didática de Lijnse e Klaassen (2004), a Fase 1 traz a necessidade de orientar e mencionar o interesse global, ou seja, o motivo do estudo do tema, denominado também como motivo global, e como ele se apresenta com relação à vida

\footnotetext{
${ }^{2}$ Acesso ao arquivo da atividade diagnóstica: <http://www.biblioteca.uesc.br/biblioteca/bdtd/201510041D.pdf>. (p. 125-126).
} 
dos estudantes, que pode ser materializada a partir das concepções prévias que os alunos manifestam.

As respostas levadas em consideração para análise foram dos alunos das duas turmas do terceiro ano, desde que estivessem presentes na atividade diagnóstica 1 (em busca dos conhecimentos prévios sobre os ADP) e na atividade diagnóstica 2 (atividade de aplicação do conhecimento). Investigamos, por meio da atividade diagnóstica 1, como o conhecimento sobre Aceleradores e Detectores de Partículas se apresentava com relação à vida desses estudantes, em busca de suas concepções iniciais, para que pudéssemos levar em consideração esses conhecimentos prévios para o desenho inicial da Sequência, relacionando o motivo de estudo do tópico - compreender os Aceleradores e Detectores de Partículas e suas influências na sociedade atual - com relação às suas implicações sociais, éticas, científicas, tecnológicas, históricas e ambientais, frente à importância de esse conhecimento ter um caráter motivador para os estudantes, conforme sugerido por Lijnse e Klaassen (2004).

\section{- Análises da atividade diagnóstica 1:}

Questão 1: Você já ouviu falar em algum momento na sua vida, reportagem de TV, jornal, na escola e/ou em conversa com alguém sobre Aceleradores e/ou Detectores de Partículas? Todos os alunos responderam sim para a questão. A seguir, temos algumas respostas dos alunos.

A22 - "Sim, já ouvi falar desse acelerador em uma aula de fisica em meu primeiro ano do ensino médio",

A12- "Sim ouvi em sala de aula com o professor que fez uma viagem a suiça e relatou a turma que teria conhecido um acelerador e detector de partícula",

A13- "Já, mas não sei como funciona”.

A maioria das respostas positivas pode estar relacionada com as discussões do professor, que, como mencionado anteriormente, teve a oportunidade de visitar o CERN, discutindo um pouco daquilo que havia aprendido durante a visita, quando esses alunos estavam na $1^{\mathrm{a}}$ série dos respectivos cursos. É interessante observar que alguns alunos ainda mencionam o LHC, e outros mencionam ter ouvido falar na TV, filmes e uma aluna por meio de um livro que leu - "Anjos e Demônios". Essas respostas nos trouxeram informações importantes como o fato de não entendermos os alunos como leigos no que se refere ao estudo do tópico, indo em busca de mais detalhes e compreensões que estes têm sobre os ADP com as questões a seguir.

Questão 2: Com que função você imagina que os Aceleradores e Detectores de Partículas foram criados? A partir dessas respostas, pode-se notar que de 23 alunos, sete trazem a percepção de que os aceleradores servem para investigar algo, seja a origem do universo, novas partículas, a estrutura da matéria, entre outras. Contudo, observamos que alguns alunos já trazem outras concepções como a relação entre os ADP e as pesquisas e a tecnologia, 
A22- "Imagino que eles foram criados para beneficiar a área que envolva tecnologia e precise desse equipamento para manusear partículas".

A13- "Para ajudar no desenvolvimento da tecnologia".

A8- "Para o melhoramento de equipamentos para a vida humana".

$\mathrm{Na}$ questão seguinte, aprofundamos um pouco mais para averiguar se os alunos conhecem equipamentos que funcionem como os ADP.

Questão 3: Você acha que existem equipamentos utilizados na vida que funcionam como, ou que são parecidos com os Aceleradores e Detectores de Partículas (ADP)? Sobre esse questionamento, os alunos se mostram um pouco divididos entre sim e não. Contudo, apenas 3 deles mencionam exemplos, os quais não estão corretos, pois nenhum dos exemplos apontados segue o princípio de funcionamento dos ADP, como o do GPS (Sistema de Posicionamento Global) que, mesmo entendendo como um "detector de pessoas", seu funcionamento difere dos ADP, que funcionam por meio de ondas de rádio emitidas por satélites. Porém, a relação estabelecida pelos alunos é interessante principalmente sobre o aspecto de que a função dessa atividade, bem como das aulas, não é definir o que está certo ou errado, mas sim favorecer a compreensão sobre o tópico.

Questão 4: Você acredita que existem fenômenos cotidianos que tenham o mesmo princípio dos Aceleradores e/ou Detectores de Partículas (ADP)? Caso sim, cite pelo menos um exemplo. Os alunos se dividem, mais uma vez, entre sim e não, apesar de dois estudantes trazerem exemplos que possuem relações com os princípios de funcionamento dos ADP como a radiação emitida por uma fonte e possível de ser detectada, e os cabos de fibra ótica que transportam as informações, principalmente pela internet, por meio da reflexão da luz, que pode se comportar como onda ou partícula, existindo relações.

A22- "Acredito que sim, os equipamentos para levar internet para lugares distantes da fonte da rede podem ter o mesmo princípio dos aceleradores".

A1- "Sim a radiação é um exemplo que possibilitou avanços para a humanidade a noção que corpos e matérias possuem massas ou não, energia”.

Contudo, a maioria (21 alunos) desconhecem os exemplos e/ou possíveis analogias, o que nos indica a pertinência em se tratar o tópico como mencionado anteriormente. Dessa forma, com a questão cinco, visamos identificar se os alunos reconhecem que os ADP podem influenciar de alguma forma na vida.

Questão 5: Pense se pesquisas desenvolvidas nos Aceleradores e Detectores de Partículas podem ou não influenciar em sua vida e no mundo em que está inserido? Tente explicar! Mais uma vez, como na questão dois, a maioria dos alunos trazem aspectos voltados para a origem do universo e estrutura da matéria. No entanto, grande parte dos estudantes ainda não indica relações dos ADP com seu cotidiano, exceto A8, quando menciona os aparelhos de diagnósticos, e A9, A11, A17 e A22 que trazem respostas sobre tecnologias, embora sem explicações sobre essa. A6, A14, A15, A18 e A21 responderam não e não sei. 
Embasado nas fases destacadas no modelo de pesquisa e desenvolvimento, em relação à estrutura didática, com relação à Fase 1, o motivo do estudo do tema se apresenta com relação à vida dos estudantes de maneira próxima, face a ideia de origem do universo e estrutura da matéria de um modo geral. Contudo, percebe-se, por meio de suas concepções iniciais, que os alunos não compreendem os Aceleradores e Detectores de Partículas e suas influências na sociedade atual. Sobre esses aspectos, estreitaremos nosso motivo global para auxiliar os alunos na compreensão dos ADP e suas implicações sociais, éticas, científicas, tecnológicas, históricas e ambientais.

\section{- Discussões e descrições referentes às aulas 01 e 02 - MOMENTO A}

O momento A, aulas 1 e 2, foi marcado pela busca da Fase 2 que leva em consideração a Fase 1, estreitando o motivo global, visando despertar o interesse dos estudantes em direção ao conhecimento, sendo importante mostrar a Ciência como uma construção humana, auxiliando os alunos a entender as atividades científicas em seu modo, com uma abordagem de ensino-aprendizagem problematizadora. Para essa fase, levamos em consideração os aspectos trazidos nas aulas 01 e 02 (com um tempo de 100 minutos) na sequência que orienta o professor no objetivo de relacionar o experimento (câmara de nuvens) em analogia ao funcionamento dos ADP atuais.

Partimos da ideia de que, atualmente, as redes sociais têm sido meio de divulgação de diversas informações, inclusive mensagens de caráter científico sensacionalista e, muitas vezes, sem veracidade (fakenews). Daí, nasce o feeling para a primeira problematização da sequência que está relacionada à reflexão dos alunos sobre as reportagens e informações acerca dos raios cósmicos (partículas) e ainda às suas implicações sociais e éticas (divulgações de informações sem veracidade). E, ainda, a condição de relacionar as notícias com a câmara de nuvens, e a câmara de nuvens com os ADP, estreitando o motivo global, que é compreender os ADP e suas implicações na vida. A seguir, um dos exemplos de mensagens que foram levadas para os estudantes.

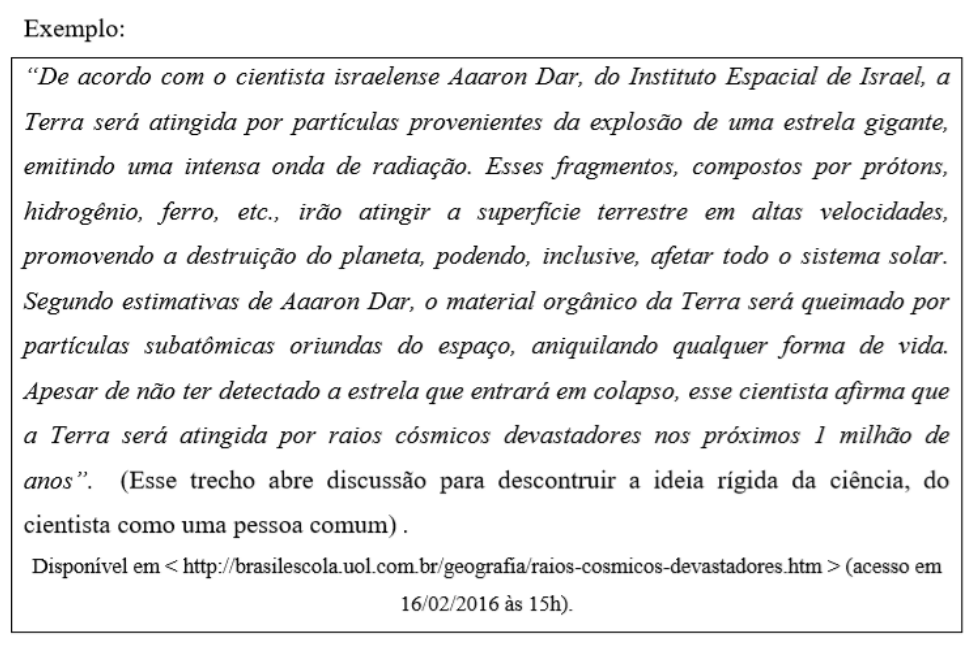

Fig. 3 - Exemplo de mensagem lida pelo professor. 
A partir de cada mensagem, o professor questionava os estudantes até que ponto essas eram verídicas, problematizando o conhecimento, como pode ser visto nos trechos abaixo:

P: Então, gente, vamos começar? ... Hoje em dia a gente tem um uso.../Acho que todo mundo aqui tem um celular, um smartphone e todos utilizam o whatsapp, e volta e meia nós recebemos umas notícias no whatsapp...e se pergunta será que é verdade mesmo...Então a gente ouve várias notícias no whatsapp, algumas são verdadeiras, outras não são...e tem umas que mesmo sem saber a veracidade acabamos divulgando. Alguém já fez isso?

Vários: (Alguns dizem que sim e outros não)

P: Alguém já recebeu aí alguma notícia no whatsapp, ou recebeu alguma notícia sobre raios cósmicos? Todo mundo já ouviu falar sobre raios cósmicos?

A1: Acho que já!

P: O que seriam os raios cósmicos na concepção de vocês? Se uma criança lhe perguntasse o que é um raio cósmico o que você iria responder?

A2: Uma coisa rápida

A3: Uma coisa que vem do céu.

$\mathrm{P}:$ A4, o que seria um raio cósmico?

A2: Uma coisa que Deus castigou (risos)

P: Raios cósmico matam?

A4: Ah, eu não sei, porque raios matam, não sei se seriam esses raios.

P: Raios matam?

Vários alunos: Matam!

P: Raios X matam?

Vários respondem: Não!

P: Mas não é um raio?

A6: Mas é diferente.

P: Mas o que é um raio então? De que raios vocês estão falando?

Todos: (incompreensivel)

P: Daqueles que vem lá das nuvens, descarga elétrica?

A4: $\dot{E}$ !

Inicialmente, é possível notar que os alunos não entendem os raios cósmicos como partículas e sim como descargas elétricas, associando as coisas que vêm do céu à religião. Alguns compreendem os raios cósmicos como algo prejudicial à vida. Então, o professor continua problematizando e lê mais uma notícia. 


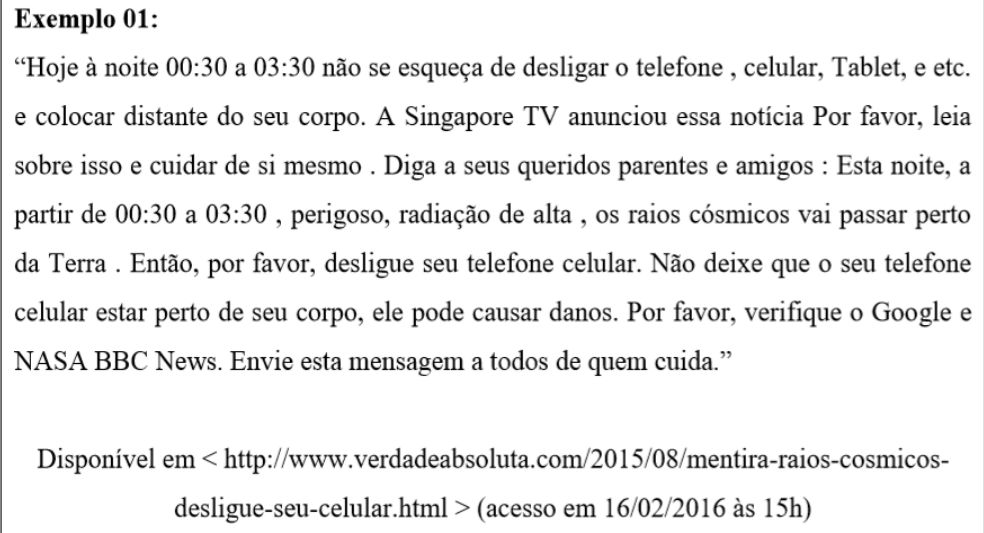

Fig. 4 - Exemplo 1 de notícia lida ao longo da aula.

Logo depois, os alunos inferem:

A4: Ah tá... já recebi isso já e depois recebi um vídeo ainda. "

$P$ : A4 recebeu, alguém mais recebeu?

A6: Eu recebi! (vários alunos mencionam ao mesmo tempo que sim)

A5: “A2" Já postou uma notícia como essa no grupo (se referindo ao grupo do whatsapp da turma)"

A2: Já, mas não era essa não.

A4: Mas era a mesma coisa... (risos)

A7: Ele colocou no grupo sim, um parecido com o outro... (incompreensível)

P: Mas vocês acham que é verdade ou que é mentira isso?

A7: Ah não sei. (incompreensível)

A4: Eu acho que, assim...porque o vídeo eu recebi de meu pai, então eu acho que é sim...é aquela coisa de pai...pai diz acontece.

A5: A minha mãe fala que se dormir e ficar com o fone de ouvido vai queimar a cara (rosto).

A partir disso, entende-se que os questionamentos do professor se apresentam como as problematizações que visam estreitar o motivo global, mas, também, como aspectos reais presentes na vida e no contexto dos alunos, representando um fator importante para a continuação do delineamento da Sequência a ser mediado com a "Câmara de Nuvens" (experimento histórico e demonstrativo da presença dos raios cósmicos que chegam constantemente a terra). Em seguida, o professor solicitou que os alunos fizessem desenhos sobre como seriam os raios cósmicos. A seguir, algumas das representações feitas pelos estudantes (Fig. 5) que ajudam a materializar um pouco das concepções que eles possuem sobre o que eles concebem como raios cósmicos. 

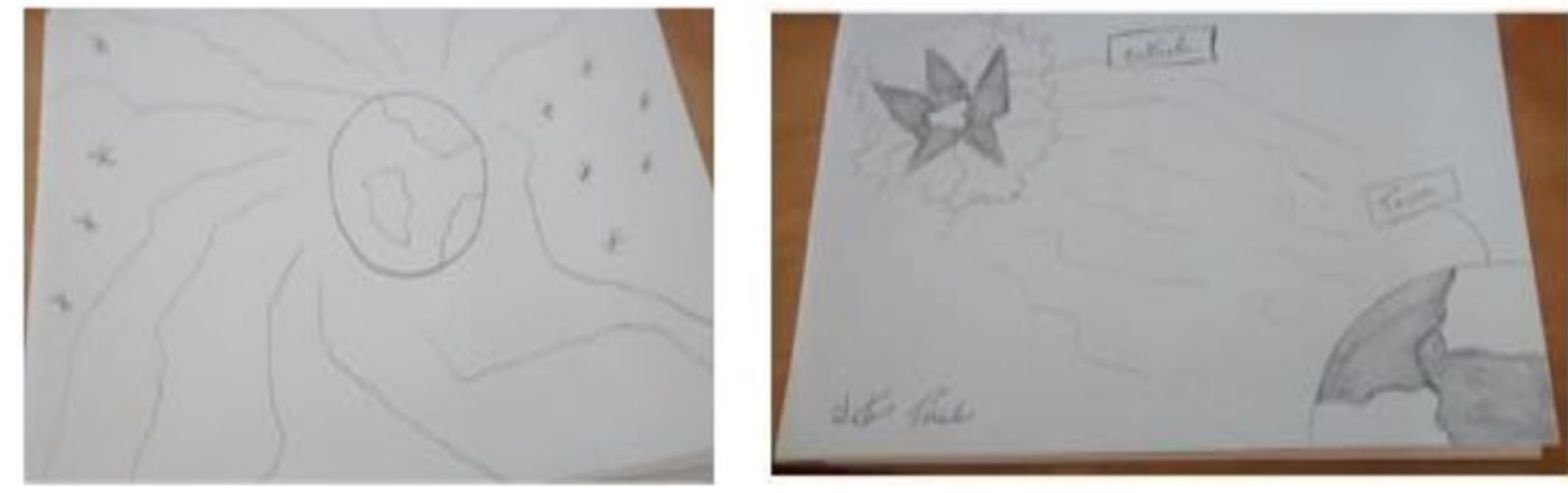

Fig. 5 - Desenhos desenvolvidos em aula pelos alunos. Fonte: dados da pesquisa.

Os raios cósmicos são partículas altamente energéticas, não se sabe ao certo como elas se originam, mas não há dúvidas que muitas descendem de explosões estelares. Tais partículas se deslocam a velocidades próximas à da luz, portanto, "raios" cósmicos não são raios. Ao entrar na Terra, essas partículas perdem energia e dão origem a outras partículas, e essas que aqui chegam, até então, são consideradas como inofensivas. É possível observar, a partir dos diálogos e dos desenhos, que os alunos têm uma concepção inicial dos raios cósmicos como "raios elétricos", o que representa uma ideia comum pelo próprio termo, destacando que, de maneira correta, eles representam os raios oriundos de fora da terra.

Contudo, há indícios, nas respostas dos alunos, que eles creem nesses raios como um risco para a vida, divulgando mensagens de notícias na internet sem ter ideia de sua veracidade, como A5 menciona sobre um colega ter compartilhado no grupo.

No momento em que os alunos estão muito curiosos, o professor inicia a montagem do experimento "Câmara de Nuvens". Para construção da "Câmara de Nuvens" nos orientamos no estudo de Pinheiro (2015), que aborda tanto a "Câmara de Nuvens", como as suas relações históricas.

Pouco antes de iniciar o experimento, os alunos receberam 05 questões para orientar a observação da "Câmara de Nuvens". Essas perguntas foram elaboradas como um guia para que os alunos estivessem atentos ao experimento e compreendessem as especificidades do funcionamento e fenômenos envolvidos. São elas: i) Do que é composta (materiais) a "Câmara de Nuvens"?; ii) Você consegue perceber ou reconhecer algum fenômeno físico na "Câmara de Nuvens"?; iii) Você associa o nome do experimento (câmara de nuvens) a algum aspecto ou característica dele? Caso sim, qual ou quais as relações; iv) Caso tenha visto algo que julgou ser diferente ou surpreendente, destaque as características; v) A "Câmara de Nuvens" parece com algo que você já viu ou utilizou na sua vida?

Essas perguntas foram como um guia para que os alunos estivessem atentos ao experimento e compreendessem as especificidades do funcionamento e fenômenos envolvidos. Como o professor leu e discutiu as questões em sala de aula com os alunos, analisaremos esse momento por meio dos diálogos na aula 01 e 02 . 
Percebe-se, então, por meio das falas, que os alunos começam a entender sobre os raios cósmicos, e que os mesmos não ocorrerem como informados nas notícias, como bem representado pela fala: “A4: Mentira! (espantada), ah não destrói não, vou dizer a meu pai, ele mandou o vídeo pra mim”. É possível perceber que a aluna realmente acreditava na capacidade dos raios cósmicos destruírem a Terra, como estava representado na notícia trabalhada na aula e recebida do pai dela no celular.

A partir dessa análise, fizemos uma reflexão sobre o quanto a Ciência ainda se apresenta distante da realidade desses alunos e da maioria das pessoas. Abordando um pouco mais sobre o experimento, o consideramos como um ponto chave, introdutório e interessante na proposta, permitindo estreitar o motivo global para despertar o interesse dos estudantes frente ao conhecimento científico, por meio das problematizações e reflexões sobre as reportagens. Entende-se que o mesmo representa bem a Fase 2, pois nela é destacada a importância de enxergar a Ciência como uma construção humana e que, consequentemente, o ensino deve orientar o aluno a entender as atividades científicas em seu modo, ao invés de transferir tais conhecimentos como um produto pronto e acabado, representando uma abordagem de EnsinoAprendizagem problematizadora (LIJNSE; KLAASSEN, 2004).

\section{- Discussões e descrições referentes às aulas 03 e 04 - MOMENTO B}

Ao prosseguir as discussões do MOMENTO B, que teve como objetivos perceber a importância dos experimentos controlados para a Ciência, compreender as principais características dos ADP e compreender o funcionamento de alguns dos principais ADP, foram implementadas 4 aulas (50 minutos cada), tendo em vista que o professor supriu o horário de um colega.

As aulas tiveram como finalidade apresentar os Aceleradores e Detectores de Partículas, relacionando-os com sua importância para a Ciência e para a vida; e, perceber a relevância dos experimentos controlados para a Ciência, tomando a "Câmara de Nuvens" como exemplo de um detector de partículas, contudo, não controlado, diferente dos detectores atuais.

Compreendendo as principais características e funcionamento dos ADP, o professor iniciou a aula relembrando os principais aspectos da aula anterior, tais como, raios cósmicos, "Câmara de Nuvens", ionização dos meios, entre outros, para, então, prosseguir a aula a partir da atividade que os alunos levaram para casa. Em posse das atividades, os alunos se reuniram inicialmente em grupos, compartilharam as suas respostas e realizaram discussões (passando cerca de 1 aula - 50 minutos - nesse momento).

Como atividade auxiliar para a sistematização, fez-se uso de um texto ${ }^{3}$ para leitura, sendo que os estudantes foram orientados a grifarem as palavras desconhecidas e circularem aquelas que já ouviram falar.

\footnotetext{
${ }^{3}$ Texto extraído do Caderno do aluno - Física, Ensino Médio - $3^{\mathrm{a}}$ série, $4^{\circ}$ bimestre. Secretaria de Educação do Estado de São Paulo.
} 
Como pode ser observado no diálogo a seguir, os alunos indicaram muitas dúvidas sobre os termos presentes no texto. É nesse momento que entendemos que a evolução do conhecimento científico se iniciará, como se pode observar na transcrição do seguinte diálogo:

P: Fizerem uma pesquisa depois, vocês vão ver.../ o eletrão não é um elétron grandão e sim o elétron, tá? (risos)... Mais algum termo que nunca tenham ouvido falar?

A13: Particulas elementares (risos).

A18: Pelo amor de Deus (com ideia de repreensão sobre o colega afirmar nunca ter ouvido falar o termo).

A13: Eu nunca ouvi falar.

P: Você faltou a minha aula foi?

A13: Eu esqueci, quer dizer provavelmente eu faltei.

$P$ : E termos que vocês já tenham ouvido falar, mas que o conceito não está bem feito (ideia de claro)?

A15: Raios cósmicos.

A16: Radiação.

P: O que mais?

A7: Campo elétrico.

A8: Campo magnético.

A13: Feixe de partículas.

P: O que mais?

A13: Raios gamas.

A17: Fonte de ions.

O professor pontua as palavras anunciadas pelos alunos no quadro como pode ser visto na Fig. 6.

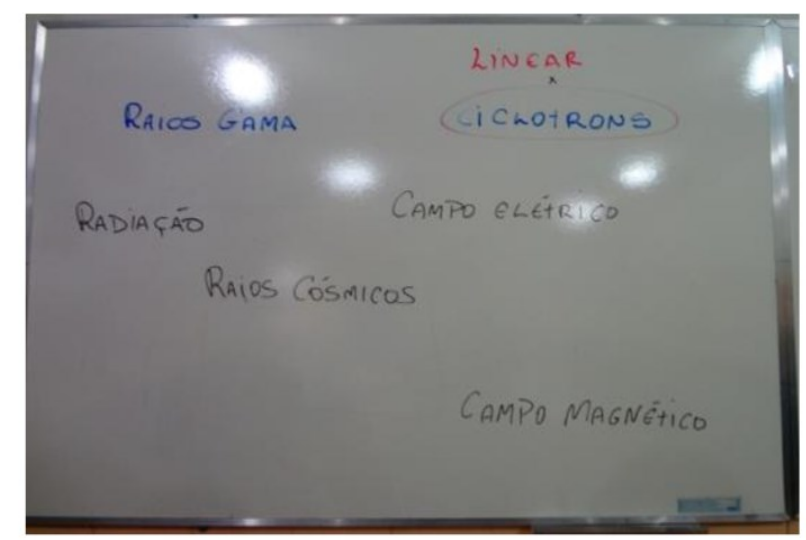

Fig. 6-Lousa com os termos. Fonte: Dados da pesquisa.

Os alunos, então, começam a compreender qual o objeto de estudo dos ADP e a entender o átomo a partir de sua estrutura, visualizando um quebra-cabeça que representa a es- 
trutura da matéria representando o universo das partículas.

Ao prosseguir as discussões do MOMENTO B, o professor argumenta e começam a aparecer os conceitos científicos: Campo magnético e campo elétrico, os quais entende-se como importantes na compreensão do funcionamento dos ADP.

\section{- Discussões e descrições referentes às aulas 07, 08, 09 e 10 - MOMENTO C}

No momento C, aulas 7, 8, 9 e 10, acontece a visita técnica, que corresponde ao tempo de 4 aulas (200 min). Como não se apresentou adequado gravar esse encontro, visto que os alunos foram divididos em grupos para conhecer o laboratório, foi feita uma breve descrição em diário de bordo pelo pesquisador com as informações descritas nesse tópico.

O laboratório foi apresentado pelos próprios pesquisadores que lá trabalham. Durante a visita, foi possível perceber expressões de interesse e surpresa dos alunos, ouvindo frases como: “O que eu preciso estudar pra fazer isso?". No laboratório, os alunos tiveram a oportunidade de observar e discutir com os pesquisadores sobre diversos aparelhos e experimentos do laboratório, como o detector de germânio, aparelhos de raio X, mamografia e contador geiger. Tiveram, ainda, a chance de conhecer pesquisas básicas e aplicadas à tecnologia sobre física médica e meio ambiente, análise de efeitos biológicos do ultrassom, e o tratamento de imagens médicas por um aparelho de raio X bem calibrado.

\section{- Discussões e descrições referentes às aulas 11 e 12 - MOMENTO D}

No encontro seguinte, aulas 11 e 12 (MOMENTO D), após a visita ao laboratório, os alunos receberam um texto de apoio e um material de orientação para esse encontro final, em que estavam previstas algumas apresentações, sendo sugerido que, baseados nas discussões e estudos durante todos os momentos anteriores, eles formassem grupos de duas e cinco pessoas para uma apresentação final. Para essa atividade, as apresentações foram feitas em forma de história em quadrinho, peça de teatro, entrevista (bate-papo), paródia ou música, poema, vídeo de divulgação e produção de um texto/reportagem para a página do facebook do instituto (obrigatório), a partir dos conhecimentos estudados (Raios Cósmicos; Aceleradores e detectores de partículas; Partículas elementares e modelo padrão; Física de partículas e o cotidiano; e o CERN).

Em busca de compreender um pouco mais sobre como esses conhecimentos se apresentaram para os alunos, fizemos uma última atividade nessa aula, denominada como atividade diagnóstica 2, com seis questões que nos trouxeram mais algumas informações e possibilitaram um aprofundamento nas análises. Aqui será dado destaque a $1^{\circ}$ questão:

$1^{\circ}$ Os aceleradores de partículas, dentre eles o famoso LHC, têm como base para os seus estudos a Física Nuclear. Baseado no princípio de funcionamento dos aceleradores de partículas, foram criados alguns instrumentos utilizados na área da medicina como auxílio ao combate de doenças, como o câncer. Quais, ou qual aparelho utilizado hoje na medicina 
elou na sua vida, que você conhece segue o princípio de funcionamento dos aceleradores e/ou detectores de particulas?

Diferentemente da primeira atividade diagnóstica 1, na qual os alunos não mencionaram aparelhos relacionados aos ADP, agora eles mencionam vários, como TV's de tubo, os aparelhos de raio X, de mamografia, e outros, ou seja, eles já reconhecem aparelhos que funcionam baseados nos princípios dos ADP. Contudo, é possível perceber que alguns alunos confundem o exame de raio X com o exame de ressonância magnética, a exemplo do comentário de A20 e A21:

A20- Basicamente os raios $X$ onde pudemos ver de perto como funciona, pode ser utilizado através de doenças de mama por exemplo.

A21- Os aparelhos de raio X requer o mesmo princípio de funcionamento dos aceleradores de partículas, usando esse princípio para análise de células e possivel diagnóstico de anormalidades.

Logo, não ficou claro para os alunos a diferença entre eles, algo a ser considerado na reestruturação para que estes não fiquem confusos, disponibilizando textos e atividades para que os alunos estruturem melhor tais conhecimentos.

De acordo com as falas, todos os alunos reconhecem a necessidade de manutenção regular desses aparelhos e dois alunos mencionam os profissionais que poderiam controlá-los. A partir dessas falas, compreendemos que esses alunos têm condições de se posicionar diante de determinadas implicações sociais, como a importância de saber que existe uma necessidade de controle desses aparelhos, o que para nós representa a Fase 4 da $T L S$, a qual se constitui como a aplicação do conhecimento em situações distintas, visando à resolução de problemas, seja na vida ou em sala de aula sobre o tópico em questão. Foi nessa fase que os estudantes, já de posse de alguns conhecimentos, posicionaram-se sobre as implicações cotidianas relacionadas ao tema (LIJNSE; KLAASSEN, 2004)

No que tange a Fase 5, o professor auxiliou o aluno a refletir sobre o conhecimento científico adquirido, destacando, ainda, que o que deveria mover os estudantes seriam os questionamentos e não as respostas, apresentando aspectos diretamente ligados à construção da ciência, demonstrando, por meio do diálogo, que não há um ponto final, uma verdade absoluta. Sobre a Fase 6, estabelece que o aprofundamento no processo de construção do conhecimento não aconteceu de maneira direta, contudo, no diálogo do professor é possível perceber algumas indicações sobre esses aprofundamentos.

Entendemos, aqui, a necessidade e a importância de os conceitos de "campo magnético" e "campo elétrico", apresentados no momento B, serem aprofundados, pois são importantes para a compreensão do funcionamento dos Aceleradores de Partículas. No entanto, a partir da análise do material, mesmo apesar de três alunos por meio das falas conseguirem fazer analogias com os conceitos, os demais permaneceram silenciosos na sala, como pode ser observado no diálogo a seguir, que ocorre no momento da aula em que o professor apresenta 
uma modelização análoga aos aceleradores de partícula, utilizando esferas, canaletas e ímãs para auxiliar na compreensão dos conceitos científicos como campo magnético, elétrico, diferença de potencial, e princípios de funcionamento dos aceleradores de partículas lineares e circulares:

P: Então vamos por partes aqui... quem direcionou a esfera no experimento?

A6: A canaleta

P: Isso, a canaleta... quem direcionava aqui as esferas?

A4: As bordas.

P: Isso as bordas, a parede, porque por inércia a tendência dele seria seguir em linha reta... então em um acelerador de partículas mesmo, não é desse jeito, então é só pra gente perceber as analogias...vamos lá então... quem acelera a partícula num acelerador de partículas é o ímã, o campo magnético ou o campo elétrico... (silêncio)... o que vai acelerar a partícula aqui (no experimento) foi o campo magnético.

A7: Mas lá (no acelerador) é o campo elétrico

P: Isso... só que o Acelerador de Partículas possui ímãs também, possui campo magnético, no AP o campo magnético não tem a função de acelerar, o campo magnético é como se fosse a canaleta, é ele que vai direcionar aquilo ali, e aí... só que eu vou ter o seguinte... um feixe de partículas girando de um lado e outro girando do outro lado... pergunta... eles estão sendo acelerados de um lado e do outro, para eles chocarem, quem que desvia?

Essas análises nos encaminham para a compreensão das modificações necessárias na sequência construída e representam uma lacuna, sendo indispensáveis estratégias que venham a favorecer a compreensão sobre o funcionamento dos ADP. A partir dessas discussões, consideramos os aspectos de reestruturação da SEA, destacando as alterações necessárias, principalmente no momento B, visando a Fase 5 e 6, ou seja, o aprofundamento dos conhecimentos científicos

De acordo com Lijnse e Klaassen (2004) sobre a Estrutura Didática da TLS, apesar de não existir uma garantia sobre a melhor forma de se ensinar um tópico, a exemplo os (ADP) utilizados aqui, é possível estabelecer critérios de comparação que levam a pensar que existem algumas formas melhores que outras.

Dessa forma, com relação à Fase 6, não encontramos, nas atividades e diálogos dos estudantes, aprofundamentos do conhecimento necessário para a compreensão do funcionamento dos ADP. Logo, entendemos que alguns aspectos precisam ser revistos, levando em conta os ADP, incluindo suas especificidades como tipos e funcionamentos atrelados aos conceitos científicos.

As modificações necessárias na sequência foram consideradas a partir das lacunas encontradas no processo ensino-aprendizagem, destacando o não aprofundamento sobre o conhecimento científico que envolve o funcionamento dos ADP, e a confusão que os alunos fizeram com os aparelhos de raios $\mathrm{X}$ e outros utilizados em exames diagnósticos. Para as modificações, fizemos uso de textos e atividades que favorecessem a construção desses conheci- 
mentos. Isso implicou na possibilidade de uma intervenção relevante para o contexto educacional, aumentando a probabilidade para uma implementação futura se apresentar melhor do que a anterior (PLOMP; NIEVEEN, 2010).

A partir dessa discussão, foi realizada uma reestruturação da sequência. O segundo Design é apresentado no quadro 2 a seguir.

Quadro 2 - Resumo do segundo desenho da Sequência de Ensino-Aprendizagem sobre aceleradores e detectores de partículas.

\begin{tabular}{|c|c|c|c|}
\hline Momentos & Objetivos & Conceitos envolvidos & Estratégias de ensino \\
\hline $\begin{array}{l}\text { Momento A } \\
\text { (4 aulas) - } \\
\text { (p. 128-145) }\end{array}$ & $\begin{array}{l}\text { - Compreender a relação } \\
\text { existente entre o experi- } \\
\text { mento, câmara de nuvens, e } \\
\text { suas relações com os Ace- } \\
\text { leradores e Detectores de } \\
\text { Partículas (ADP); } \\
\text { - Desmistificar os raios cós- } \\
\text { micos; } \\
\text { - Compreender o que são os } \\
\text { raios cósmicos; } \\
\text { - Entender a relação entre o } \\
\text { experimento câmara de nu- } \\
\text { vens com os ADP; } \\
\text { - Conhecer Aceleradores e } \\
\text { Detectores de Partículas. }\end{array}$ & $\begin{array}{l}\text { Partículas subatômicas, } \\
\text { raios cósmicos e radiação } \\
\text { ionizante. }\end{array}$ & $\begin{array}{l}\text { - Apresentação de trechos } \\
\text { de internet, destacando o } \\
\text { "perigo" dos raios cós- } \\
\text { micos (p. 134-135). } \\
\text { - Construção, apresenta- } \\
\text { ção e discussão de fe- } \\
\text { nômenos e aspectos en- } \\
\text { volvidos na construção e } \\
\text { funcionamento da "Câ- } \\
\text { mara de Nuvens", bem } \\
\text { como as relações exis- } \\
\text { tentes entre a mesma } \\
\text { com os ADP (p.128-133; } \\
\text { p.136). } \\
\text { - Atividade sobre a desco- } \\
\text { berta de novas partículas } \\
\text { (p. 137-138). } \\
\text { - Texto para discutir o } \\
\text { "Caso de César Lattes" } \\
\text { (p.140-143). }\end{array}$ \\
\hline
\end{tabular}




\begin{tabular}{|c|c|c|c|}
\hline $\begin{array}{l}\text { Momentos B } \\
\text { (5 aulas) }\end{array}$ & $\begin{array}{l}\text { - Apresentar os Aceleradores } \\
\text { e Detectores de Partículas, } \\
\text { demonstrando a importân- } \\
\text { cia deles para as pesquisas } \\
\text { científicas e identificar a } \\
\text { presença deles na vida. } \\
\text { - Conhecer os Aceleradores e } \\
\text { para que servem, incluindo } \\
\text { a importância dos detecto- } \\
\text { res no processo de investi- } \\
\text { gação das partículas; } \\
\text { - Compreender as principais } \\
\text { características e funciona- } \\
\text { mento dos Aceleradores; } \\
\text { - Reconhecer os Acelerado- } \\
\text { res no cotidiano }\end{array}$ & $\begin{array}{l}\text { Tipos de Aceleradores e } \\
\text { Detectores de Partículas, } \\
\text { bem como os conceitos } \\
\text { físicos que envolvem o } \\
\text { seu funcionamento, tais } \\
\text { como: } \\
\text { - Diferença de potencial; } \\
\text { - Campo elétrico; } \\
\text { - Campo magnético } \\
\text { - Conservação de ener- } \\
\text { gia. }\end{array}$ & $\begin{array}{l}\text { - Leitura, análise e discus- } \\
\text { são a partir de um texto } \\
\text { sobre raios cósmicos e } \\
\text { os ADP (p. 144-145). } \\
\text { - Fornecimento de materi- } \\
\text { ais para que os alunos } \\
\text { tentem modelizar os ti- } \\
\text { pos de ADP (p. 150- } \\
\text { 153). } \\
\text { - Atividade sobre aspectos } \\
\text { do campo magnético e } \\
\text { ondas eletromagnéticas } \\
\text { (p. 154-157). } \\
\text { - Leituras e atividades } \\
\text { sobre os Raios X consi- } \\
\text { derando seu contexto } \\
\text { histórico, e as radiogra- } \\
\text { fias (p.158-164). } \\
\text { - Discussão a partir de um } \\
\text { texto sobre as implica- } \\
\text { ções tecnológicas a partir } \\
\text { dos estudos desenvolvi- } \\
\text { dos nos ADP (p.165- } \\
\text { 167). }\end{array}$ \\
\hline $\begin{array}{l}\text { Momento C } \\
\text { (4 aulas) }\end{array}$ & $\begin{array}{l}\text { - Compreender as relações } \\
\text { que existem entre os acele- } \\
\text { radores de partículas e a so- } \\
\text { ciedade em que vivemos; } \\
\text { - Entender os motivos para } \\
\text { realização de investimentos } \\
\text { tão elevados em pesquisas } \\
\text { científicas, como o caso do } \\
\text { LHC, para a nossa socieda- } \\
\text { de; } \\
\text { - Conhecer um Centro de } \\
\text { Pesquisas em Ciências e } \\
\text { Tecnologias das Radiações; } \\
\text { - Oportunizar a vivência com } \\
\text { cientistas da área de radia- } \\
\text { ções; } \\
\text { - Perceber a relação entre as } \\
\text { pesquisas científicas e o } \\
\text { avanço da medicina. }\end{array}$ & $\begin{array}{l}\text { - Tecnologias dos } \\
\text { Aceleradores e Detec- } \\
\text { tores de Partículas; } \\
\text {-Equipamentos de } \\
\text { radiodiagnósticos; } \\
\text {-Radiações. }\end{array}$ & $\begin{array}{l}\text {-Os alunos conhecerão } \\
\text { um centro de pesquisa } \\
\text { em ciências e tecnologi- } \\
\text { as da radiação, próximo } \\
\text { a suas escolas, bem } \\
\text { como os experimentos } \\
\text { desenvolvidos nesse } \\
\text { centro; } \\
\text { - Receberão um texto } \\
\text { sobre a influência dos } \\
\text { ADP na sociedade } \\
\text { moderna e o material } \\
\text { para prepararem a } \\
\text { apresentação para a } \\
\text { próxima aula (p. 172- } \\
\text { 176). } \\
\text {-Caso não possam visitar } \\
\text { o Centro, farão a leitura } \\
\text { e discussão do texto em } \\
\text { sala de aula e organiza- } \\
\text { rão as apresentações para } \\
\text { a aula seguinte. }\end{array}$ \\
\hline
\end{tabular}




\begin{tabular}{|c|c|c|c|}
\hline $\begin{array}{l}\text { Momento D } \\
\text { ( } 2 \text { aulas) }\end{array}$ & $\begin{array}{l}\text { - Sistematizar e socializar os } \\
\text { conhecimentos sobre física } \\
\text { de partículas adquiridos ao } \\
\text { longo de todo o curso; } \\
\text { - Relacionar os conhecimen- } \\
\text { tos físicos com outras áreas } \\
\text { do conhecimento; } \\
\text { - Associar conhecimentos } \\
\text { físicos com situações do } \\
\text { cotidiano. }\end{array}$ & $\begin{array}{l}\text { Não há um conteúdo } \\
\text { específico, uma vez que } \\
\text { esta aula trata da culmi- } \\
\text { nância do curso, em que } \\
\text { os alunos irão apresentar } \\
\text { os trabalhos por eles } \\
\text { produzidos, considerando } \\
\text { os conhecimentos em } \\
\text { tornos dos ADP, como o } \\
\text { funcionamento e fenô- } \\
\text { menos envolvidos. }\end{array}$ & $\begin{array}{l}\text { Os alunos receberão uma } \\
\text { atividade diagnóstica (p. } \\
\text { 179-181) a ser respondida } \\
\text { em aproximadamente } 20 \\
\text { min. Em seguida, serão } \\
\text { apresentados os trabalhos } \\
\text { desenvolvidos pelos alu- } \\
\text { nos. }\end{array}$ \\
\hline
\end{tabular}

Como pode ser observado, os objetivos e conteúdos passaram por poucas ou quase nenhuma mudança. As modificações principais estão situadas nas estratégias de ensino, pois aumentamos a gama de atividades com a intenção de favorecer a compreensão dos alunos com relação ao conhecimento objetivado, a partir das lacunas de aprendizagem que foram percebidas durante a primeira implementação, trazendo atividades que estruturam os conceitos físicos que envolvem o eletromagnetismo e a compreensão sobre os raios X, para evitar a confusão que os alunos fizeram em alguns momentos, como pôde ser visto nas falas dos alunos na atividade diagnóstica 2 .

Dessa forma, para superar as lacunas e favorecer ainda mais o processo de evolução da aprendizagem, consideramos, para a escolha das novas estratégias, textos e atividades que trouxessem o contexto histórico das descobertas, pois estas podem favorecer a compreensão para uma visão não distorcida da Ciência, mencionado por Melzer (2012).

\section{Considerações finais}

Retomando o objetivo geral da pesquisa, buscamos investigar a potencialidade de uma Sequência de Ensino-Aprendizagem sobre os ADP, a partir da estruturação, implementação, avaliação e reestruturação (processo cíclico) pautada nos pressupostos teóricos e metodológicos da TLS e analisar como a sequência se apresentou após implementação no contexto escolar, ou seja, se a mesma favoreceu aspectos relacionados ao processo de ensinoaprendizagem sobre o tema, investigando a partir da primeira implementação as suas limitações, reestruturando-a e implementando-a em um novo contexto. Devido a alguns imprevistos no desenvolvimento da pesquisa, especialmente no que se refere ao tempo, não foi reimplementada a sequência em um segundo contexto, o que nos impede de defini-la como uma TLS.

Percebemos que a primeira implementação da sequência, analisada a partir das fases da $T L S$, proporcionou reflexão dos alunos sobre as reportagens e informações relacionadas aos raios cósmicos (partículas) e ainda às suas implicações sociais, éticas (divulgações de informações sem veracidade), científicas (aspectos relacionados aos fenômenos físicos entre a "Câmara de Nuvens" e os ADP), tecnológicas (sobre as implicações das pesquisas relaciona- 
das aos ADP com relação a exames e aparelhos), históricas (a evolução da Ciência a partir das pesquisas desenvolvidas nos aceleradores) e ambientais (a partir do uso dos detectores para analisar índices de contaminação no ambiente).

Entretanto, também houve lacunas que foram consideradas no processo de reestruturação, principalmente sobre o não aprofundamento do conhecimento científico, o que esperamos que ocorra por meio das novas atividades propostas. De acordo com Tiberghien et al. (2009), os alunos, no final de uma TLS, constroem um conhecimento intermediário entre o conhecimento inicial e o objetivado. Dessa forma, a função da TLS é proporcionar aos alunos a compreensão sobre um conhecimento, progressivamente.

\section{Referências}

ALVES-FILHO, J. P. Atividades Experimentais: Do Método a Prática Construtivista. 2000. Tese (Doutorado em Educação em Ensino de Ciências Naturais) - UFSC, Florianópolis.

ARAÙJO, M. C. Energia Nuclear e Radioatividade na Escola de nível médio: um olhar a partir dos acidentes nucleares. 2013. Dissertação (Mestrado Profissional em Ensino de Ciências e Matemática) - PUC, Belo Horizonte.

ARAÚJO, M. C.; HOSOUME, Y. A Física Moderna e Contemporânea no Ensino Médio: algumas tendências da última década. In: SIMPÓSIO NACIONAL DE ENSINO DE FÍSICA, XX, 2013, São Paulo.

BATISTA, C. A. Física Moderna e Contemporânea no Ensino Médio: subsídios teóricometodológicos para a sobrevivência do tópico radioatividade em ambientes reais de sala de aula. 2015. Dissertação (Mestrado em Educação em Ensino de Ciências) - UESC, Ilhéus.

BATISTA, C. A. S.; SIQUEIRA, M. Um olhar da Transposição Didática para uma sequência de ensino sobre radioatividade baseada na estrutura da TLS. In: SIMPÓSIO NACIONAL DE ENSINO DE FÍSICA, XXI, 2015, Uberlândia. v. único.

BATISTA, C. A. S.; SIQUEIRA, M. A inserção da Física Moderna e Contemporânea em ambientes reais de sala de aula: uma sequência de ensino-aprendizagem sobre a radioatividade. Caderno Brasileiro de Ensino de Física, Florianópolis, v. 34, n. 3, p. 880-902, dez. 2017. Disponível em: <https://periodicos.ufsc.br/index.php/fisica/article/view/21757941.2017v34n3p880/35527>.

BATISTA, C. A; SIQUEIRA; M; REIS, Y. Design de uma TLS sobre a Radioatividade. In: ENCONTRO NACIONAL DE PESQUISA EM EDUCAÇÃO EM CIÊNCIAS, X, 2015, Águas de Lindóia, São Paulo. Anais... 
CHEVALLARD, Y. La Transposicion Didactica: Del saber sabio al saber enseñado.1. ed. Argentina: La Pensée Sauvage, 1991.

COLLECTIVE Design-Based Research: An Emerging Paradigm for Educational Inquiry. Educational Researcher, v. 32, n. 5, p. 1-5, 2003.

DELIZOICOV, D.; ANGOTTI, J. A.; PERnAMBUCO, M. M. Ensino de Ciências: Fundamentos e Métodos. São Paulo: Cortez, 2011.

KNEUBIL, F. B. O percurso epistemológico dos saberes e a equivalência massa energia. 2014. Tese (Doutorado em Educação), USP, São Paulo.

LEACH, J.; SCOTT, P. The concept of learning demand as a tool for designing teaching sequences. In: MEETING RESEARCH-BASED TEACHING SEQUENCES, 2000, Université Paris VII, France.

LIJNSE, P. L. La recherche-developpement: une voie vers une 'structure didactique' dela physique empiriquement fondee. Didaskalia, v. 3, p. 93-108, 1994.

LIJNSE, P; KLAASSEN, C. W. J. M. Didactical structures as an outcome of research on teaching-learning sequences? International Journal of Science Education, London, v. 26, n. 5, p. 537-554, 2004.

MÉHEUT, M; PSILLOS, D. Teaching-learning sequences: Aims and tools for science education research. International Journal of Science Education, London v. 26, n. 5, p. 515-535. Abril 2004.

MELZER, E. E. M. Do saber sábio ao saber a ensinar: a transposição didática do conteúdo modelo atômico de livros de química. 2012. Dissertação (Mestrado em Educação em Ciências e em Matemática) - Universidade Federal do Paraná, Curitiba.

MONTEIRO, M. A.; NARDI, R.; BASTOS FILHO, J. B. Física Moderna e Contemporânea no ensino médio e a formação de professores: desencontros com a ação comunicativa e a ação dialógica emancipatória. Revista Electrónica de Investigación en Educación en Ciencias, v. 8, n. 1, p. 1-13, 2012.

MUENCHEN, C.; DELIZOICOV, D. Os três momentos pedagógicos e o contexto de produção do livro "Física". Revista Ciência e Educação, Bauru, v. 20, n. 3, p. 617-638, 2014. 
NICOLAU, J.; GURGEL, I.; PIETROCOLA, M. Estrutura Baseada em Fluxo: Sequência de Ensino-Aprendizagem Sobre Relatividade do Tempo. In: ENCONTRO NACIONAL DE PESQUISA EM EDUCAÇÃO EM CIÊNCIAS, IX, 2013, Águas de Lindóia.

OSTERMANN, F.; MOREIRA, M. A. Atualização do currículo de física na escola de nível médio: um estudo dessa problemática na perspectiva de uma experiência em sala de aula e da formação Inicial de professores. Caderno Catarinense de Ensino de Física, Santa Catarina, v. 18 , n. 2, p. 135-151, ago. 2001.

PAIS, L. C. Didática da matemática: Uma análise da influência francesa. 3. Ed. Belo Horizonte: Autêntica Editora, 2011.

PEREIRA, P. A; OSTERMANN, F. Sobre o ensino de física moderna e contemporânea: uma revisão da produção acadêmica recente. Investigação em Ensino de Ciências, Porto Alegre, v. 14, n. 3, p. 393-420, 2009.

PESSANHA, M. B.; PIETROCOLA, M. O ensino de estrutura da matéria e aceleradores de partículas: uma pesquisa baseada em design. Revista Brasileira de Pesquisa em Educação em Ciências, v. 16, n. 2, p. 361-388, 2016.

PIETROCOLA, M. Inovação Curricular e Gerenciamento de Riscos Didático Pedagógicos: o ensino de conteúdos de Física Moderna e Contemporânea na escola média. Faculdade de Educação, USP. Out. 2010.

PINHEIRO, L. A. A câmara de nuvens: uma abordagem integrada entre a Física Clássica e a Física Moderna. Caderno Brasileiro de Ensino de Física, v. 32, p. 517-528, 2015.

PINTO, A. C; ZANETIC, J. É possível levar a física quântica para o ensino médio? Caderno Catarinense de Ensino de Física, Florianópolis, v. 16, n. 1, p. 7-34, 1999.

PLOMP, T. E.; NIEVEEN, N. An Introduction to Educational Design Research. 3 rd. Netzodruk Enschede, 2010. p. 10-51.

SILVA, Y. A. R.; SIQUEIRA, M.; BATISTA, C. A. S. Aceleradores e detectores de partículas sob o olhar da Transposição Didática. In: ENCONTRO NACIONAL DE PESQUISA EM EDUCAÇÃO EM CIÊNCIAS, 2015, Águas de Lindoia.

SIQUEIRA, M. Do visível ao indivisível: uma proposta de Física de Partículas Elementares para o Ensino Médio. 2006. Dissertação (Mestrado em Educação) - USP, São Paulo. 
TERRAZAN, E. A. A inserção da física moderna e contemporânea no ensino de física na escola de $2^{\circ}$ grau. Caderno Catarinense de Ensino de Física, Florianópolis, v. 9, n. 3, p. 209-214, dez. 1992.

TIBERGHIEN, A.; VINCE, J.; GAIDIOZ, P. Design-based Research: Case of a teaching sequence on mechanics. International Journal of Science Education, v. 31, n. 17, p. 22752314, 2009. 